\title{
En torno al concepto de religiosidad popular
}

\author{
Claudia Lira Latuz \\ Instituto de Estética, Facultad de Filosofía, Pontificia Universidad Católica de Chile. \\ cliral@uc.cl
}

Aisthesis, la revista chilena de investigaciones estéticas que nació en el año 1966, dio cuenta de la temática de la religiosidad popular solo en su edición número 20. En muchos de los artículos donde se hace alusión a lo popular, no se habla directamente de la religiosidad sino de la "cultura popular" y, solo algunas veces, se alude tangencialmente al arte popular, aunque el concepto resulte un poco forzado, pues ahora, cuando se cuenta con un poco más de herramientas de estudio gracias a las reflexiones de Ticio Escobar, entre otros autores, podemos hablar con propiedad de una estética popular. Esta se entiende como la producción simbólica derivada de sistemas de creencias y prácticas sincréticas, que determinan y dialogan con una "apariencia", cuya función es expresarlos y transmitirlos, revelando sentidos que fundamentan las identidades latinoamericanas. De ahí que a partir de lo escrito sobre cultura y religiosidad popular nos propongamos destacar aquellas ideas que nos parecen que sentaron precedentes $y$, de alguna manera, pueden todavía ser puntos de referencia para futuras investigaciones. Finalmente, tenemos que hacer notar que la conceptualización respecto a la religiosidad popular proviene fundamentalmente de la antropología, de la sociología e incluso de la teología; solo tardíamente, se ha comenzado a realizar una lectura estética del fenómeno.

En Aisthesis 20, publicada en el año 1987, encontramos la primera noticia en torno a la temática de la religiosidad popular a propósito de una ponencia de Jaime Moreno, "Acercamiento antropológico a la religiosidad popular" (15-18), donde se expone una definición de esta a partir de un análisis comparativo entre la religión oficial, catalogada de apolínea, en cuanto tiende al orden, a la purificación y a las reglas; y la popular, considerada dionisíaca, extática, mito-poética y rinencefálica. 
Según Moreno, la religiosidad popular, entendida como una expresión libre de lo oficial de la religión y en contraste con lo racional y estructurado que lo caracteriza, se presenta bajo los signos de lo dionisíaco, "donde se privilegia la acción festiva, donde se vuelca la capacidad inventiva, improvisación y experiencial de lo mistérico en forma puntual y transeúnte" (16). De ahí que el autor proponga que la religiosidad popular expresa lo instintivo, emocional y corporal ante lo sagrado, pues sus manifestaciones corresponden a expresiones que derivan de la parte rinencefálica del cerebro a cargo de lo afectivo-corporal y de las respuestas instintivas, que procesan los estímulos y respuestas emocionales relacionadas con el ritmo. Por otro lado, Moreno propone que la religiosidad popular es también mito-poética, en cuanto deriva de experiencias cotidianas que serán articuladas en mitos y en una poética orientada a develar y explicar el sentido de la existencia. Si bien utiliza los conceptos de lo apolíneo y lo dionisíaco para tensar y aclarar las diferencias entre ambas disposiciones religiosas, aclara que estas no se encuentran desvinculadas, sino que fluyen de una a la otra, siempre. Finalmente, destaco que Moreno declara que la lectura de un libro de Gabriel Salazar lo ha impresionado, y a partir de sus reflexiones sobre la cultura del peón, del gañan, de la proletaria o del bajo pueblo, puede decirse que, si "esos actores re-presentan su religión, hablaremos ahí de religiosidad popular” (18).

A partir de este último punto, nos referiremos al artículo publicado en la revista Aisthesis 27, de 1994, titulado "Notas sobre el concepto de cultura popular: en torno a las formulaciones y a la unidad del concepto", de Miguel Alvarado (57-79), pues a pesar de que en él no se hace especial mención a la religiosidad popular, sí se pretende cercar no solo la noción de cultura popular, que incluye a la religiosidad como una de sus expresiones, sino que además se destaca a dos intelectuales que han intentado definir la identidad latinoamericana a partir de las manifestaciones de la cultura popular.

El primero de ellos es el antropólogo peruano Manuel Marzal, de vasta producción intelectual derivada de su trabajo en terreno. Apoyado en las ideas de Cliford Geertz, Marzal plantea que la religión cumple una función ordenadora en la cultura, sosteniéndose en el símbolo y en el ritual, "el cual muestra una 'perspectiva' en la mente de los hombres", que aporta "un modo peculiar de ver la vida y de construir el mundo" (62). Por otro lado, siguiendo las ideas de Oscar Lewis, quien estableció que en Latinoamérica existe una "verdadera cultura de la pobreza", en cuanto los pobres no son una subcultura sino una determinada perspectiva de mundo, de la cual deriva no solo una ética sino también una estética, Marzal sostiene que si bien los pobres conservan un "modo" original de ver, convivir y enfrentar el mundo, que es basal e impregna a las otras capas sociales, lo popular no se circunscribe únicamente a su visión.

El valor de las reflexiones de Marzal, especialmente en relación con el último comentario que realiza Moreno respecto de los apuntes de Salazar, estriba en que logra comprender que lo popular no se circunscribe a los pobres en tanto desposeídos, sino en tanto que en ellos se conserva en mayor medida el sincretismo latinoamericano post-conquista, producto de múltiples procesos de asimilación, rechazo 
y transformación de los contenidos epistemológicos y religiosos impuestos por la cosmovisión española, superpuestos a los conocimientos, prácticas, materialidades y creencias precolombinas, que no pudieron ser destruidas del todo por la penetración europea; es en esta resistencia-receptividad, dice Marzal, donde reside el mayor valor de esta "cultura de los pobres". De esta manera, el autor afirma que "la religiosidad popular no solo penetra en su mundo sino también en las capas dominantes, en tanto el concepto popular no significa solamente pobre. Las formas religiosas de los dominantes se ven influenciadas por la de los dominados, a partir de una matriz cultural sincrética que se proyecta en lo religioso" (63). Es posible encontrar en estos comentarios dos elementos cruciales en la reflexión en torno a lo popular; por un lado, el tema de los desposeídos, que en la mayoría de los casos, son identificados no solo como los vencidos sino también como los que perdieron el contacto con sus tradiciones; por otro lado, se habla de la fuerza soterrada con que lo popular se impone en la cultura oficial o dominante. En relación con esto, Marzal señala que el sincretismo, en cuanto "expresión cultural que genera síntesis [...] producto de la interacción dialéctica de los sistemas en contacto" (64), permitió resguardar tanto la relación con la naturaleza como con los seres sagrados, a través de prácticas que asumieron y re-semantizaron las creencias y ritos foráneos, expresando una verdadera síntesis. Es importante destacar una de las prácticas donde, según este investigador, se conservó lo propio: la autonomía respecto de la jerarquía de la iglesia expresada en la creencia en los santos patronos como una velada continuidad de la fe en los ancestros del clan. Es posible comprobar que esta creencia aún se mantiene vigente en la actualidad; de hecho, en un trabajo en terreno realizado el 31 de noviembre del año en curso, un habitante de la comunidad de Cobija, en el norte del país, ante la pregunta de si era católico, respondió: "No soy católico, los católicos van a misa, yo no voy a misa. Yo creo en los santos, participo en la fiesta del santo patrono del pueblo. Además, creo en las almitas (antepasados)". Marzal también hace mención a la utilización mágica de los elementos rituales católicos, tanto de objetos como de oraciones y cantos. Ejemplo de esto es el uso de la cruz en los campos de cultivo y en las cumbres de las montañas en el área andina.

Por último, Marzal da cuenta de tres formas posibles de sincretismo, las que muchas veces coexisten en distintos lugares. En algunos casos, se "acepta el aporte externo y se le da un significado propio"; en otros, "se conserva la pauta cultural propia y se le da significado externo, proveniente de la cultura que se está penetrando"; y a veces, "se acepta la pauta externa, pero a un significado original se le añade un nuevo significado" (64).

El otro intelectual destacado por Miguel Alvarado es el sociólogo Pedro Morandé, quien extrae de Gadamer los conceptos de historicidad y de tradición, estableciendo que los valores culturales son fruto "del devenir histórico de las representaciones y las concepciones propias de una cultura, en tanto nada en la cultura se crea gratuitamente, sino que todo tiene que ver con un pasado tanto de significados como de 
símbolos y signos. El sentido de la historia presente tiene su base en los significados y en las representaciones generadas en el pasado" (68). A partir de esto, Morandé establece que la fase posterior a la conquista y anterior a la formación de los estadosnaciones, es decir, la época barroca, fue cuando nació y se desarrolló la esencia de la identidad latinoamericana, la cual se estructura a partir de una relación dialógica entre las creencias y prácticas precolombinas y las ibéricas, arraigándose en un tipo de arte y en una estética.

Morandé propone que el barroco es un "estilo cultural" en el que se funda y asienta la cultura latinoamericana, ya que en él se intentó, entre otras cosas, "integrar oralidad y escritura a través de la representación, por eso la síntesis cultural de América Latina es cultica y no ideológica" (71). El problema fundamental es que en la formación de los estados-naciones no se valorizó esta síntesis, sino que más bien fue ignorada-rechazada, proyectándose hacia lo foráneo y la modernidad. De ahí que finalmente Morandé afirme que el arte popular posee una estética barroca en la cual se hace presente icónicamente la dimensión expresiva, unida a la esfera de lo dramático, de nuestra identidad, en tanto este arte, incluso asumiendo influencias del arte de masas, mantiene su dimensión barroca, tanto como exacerbación de la forma como búsqueda de síntesis, expresando con ello nuestra matriz cultural y su realización histórica $(71)$.

Esta propuesta de Morandé, si bien no forma parte de las referencias del artículo escrito por Claudia Lira, "La animita en el ámbito del Arte" (74-97), publicado en el número 32 de Aisthesis, es una estimulante propuesta para una re-lectura de la estética que está en la base de la producción simbólica animita, en cuanto su nacimiento y función pertenecen a la esfera de lo dramático y su apariencia responde a una síntesis que exacerba la forma. Esta característica, que he denominado en otros contextos como "estética de la saturación o de la acumulación", tiende a ser expansiva y desbordante, en la medida en que, según sus cultores, se vuelve más milagrosa; además, suele ser sentida como indecente (concepto que ya aparece como juicio moral-estético en las crónicas) por los sectores cultos, debido a que expone públicamente el dolor y la fe, la cual, según la religión oficial, debe ser íntima y mediatizada por las reglas otorgadas por la Iglesia. Del mismo modo, esta manifestación tiende a la síntesis, en el sentido en que acoge no solo los antecedentes precolombinos e ibéricos, sino también los elementos que vienen de la sociedad de masas, adaptándolos a las necesidades estéticas y religiosas, tanto del sujeto como del objeto animita. Por otro lado, debido quizás a las temáticas clásicas de la revista, este artículo intentó leer y situar la animita en el ámbito del arte, reconociendo que es una manufactura estética perteneciente a la religiosidad popular, en todas sus dimensiones: la de las creencias, las prácticas y la estética. Intento inútil debido no solo a que su culto pertenece a la mentalidad no moderna donde se inserta el concepto arte, sino además porque era innecesario valorarla desde una conceptualización ajena. Sin embargo, fue preciso reflexionar desde esa epistemología para valorizar su presencia en cuanto objeto que revela una 
identidad, la del sincretismo visual e ideológico propio de Latinoamérica, ya que como objeto estético, que sintetiza un grupo de creencias y prácticas, es transversal a todas las clases sociales.

En ese mismo número de Aisthesis, se encuentra un artículo particularmente interesante del sociólogo Cristián Parker: "Cultos y religiones populares en América Latina: identidades entre la tradición y la globalización” (47-59). Me parece destacable porque evidencia la nueva fase ideológica en la que vivimos y en la que debemos situar nuestras reflexiones. Muchos autores continúan centrados en la dicotomía entre lo moderno y lo pre-moderno para referirse a las creencias, prácticas y materialidades de la religiosidad popular. Sin embargo, ahora nos encontramos de lleno en el fenómeno de la globalización, no solo entendido como una cultura de la tecnología, sino también como un fenómeno fundamentalmente económicocapitalista que permea las sociedades conduciéndolas al consumo y a las relaciones mediatizadas. En este sentido, cabe preguntarse, como lo hace Parker, “'hasta qué punto, y a pesar de la cultura hegemonizante que globaliza y enfatiza el consumo y el pragmatismo, la gente mantiene sus valores y sus identidades?, ¿cómo se conjuga esto con la vitalidad religiosa del pueblo latinoamericano?" (49). Estas preguntas nos conducen a reflexionar sobre la realidad y permanencia de la religiosidad popular en Latinoamérica, sobre su posible desdibujamiento e, incluso, desaparición, debido a que la secularización propia de la modernidad se ve ahora exacerbada por objetos y demandas que proponen una renuncia total a la conexión no solo con el paisaje natural sino además con aquellas entidades que la religiosidad popular siente que la sostienen. En este punto es relevante introducir la perspectiva teológica que Antonio Bentué expone en su artículo "Religiosidad e inculturación en Chile" (17-25); aquí, el autor plantea que la secularización no extermina las creencias y prácticas de la religiosidad popular, ya que estas no están fundamentadas en el resultado que se espera de ellas (aunque este es crucial), sino en el sentido que otorgan. Como ejemplo de esto presenta el caso de una machi que se atiende en el sistema de salud pública y que no ve contradicción en que sus pacientes también lo hagan, pues el buen resultado de la medicina occidental no resuelve el origen y sentido de la enfermedad, los cuales están ligados a relaciones mítico-mágicas entre el ser humano y su entorno natural; es esto lo que debe ser comprendido y saneado para que la enfermedad no llegue a depositarse nuevamente en el cuerpo. De alguna manera, la medicina occidental resuelve el síntoma, pero no el trasfondo de la enfermedad, el cual es espiritual y está ligado a una lectura religiosa de la realidad, la que seguirá operando mientras se viva inserto en una relación estético-afectiva con el mundo. En este sentido, Bentué señala que uno de los rasgos fundamentales de la religiosidad popular tiene que ver con el sentir y entender la realidad como misteriosa, tremenda y asombrosa. Por eso, quien se encuentra inserto en esta dimensión asume la absoluta sujeción a las fuerzas del universo, contra las cuales la tecnología avanzada no puede, en última instancia, hacer nada. Esa pequeña o gran certeza de una relación distinta o reverente ante un 
universo que jamás controlaremos, se presenta como el resguardo que la religiosidad popular posee ante el consumismo y la completa secularización que la sociedad capitalista-tecnologizada intenta imponer. Así se entiende que el culto híbrido a la Virgen de Guadalupe en México, presentado por Parker como un caso de estudio que revela esta protección "espiritual", haya sido lo que sobrevivió y se conservó no solo durante la revolución, sino que sigue siendo un factor aglutinante en la vorágine de las migraciones y seducciones que la globalización impone sobre las sociedades latinoamericanas. De ahí que este autor asevere que en la sociedad global,

donde los medios de comunicación eliminan las barreras y fronteras entre las naciones, los cultos populares latinos constituyen un factor de identificación cultural con poderosos arraigos en la mentalidades colectivas. Tal es así que donde veamos a grupos de latinoamericanos, en Norteamérica y en Europa (incluso, agregamos en Chile, como ocurre con peruanos, especialmente radicados en Santiago) sus encuentros estarán marcados por la revitalización de los antiguos cultos populares que dejaron en su tierra de origen (56).

Esta "defensa" contra la globalización apoyada en imágenes, creencias y prácticas que los inmigrantes llevan consigo, no solo se sostiene en lo anterior sino también en el cuerpo presente de los que danzando, bebiendo y comiendo, gozan en un cara a cara la vida que comparten, a través de la pertenencia a una tierra y a un santo patrono que la resguarda. Así, lo estético se manifiesta aquí como el modo fundamental en que las sociedades latinoamericanas conviven reivindicando la conexión consigo mismas, los otros y lo Otro que las constituyen. 